\title{
E-Ethics and Higher Education: Do Higher Education Challenges Make a Case for a Framework for Digital Research Ethics?
}

\author{
I-K MORRIS, University of Southampton
}

\begin{abstract}
Ethical guidance and understanding of research methods in Higher Education needs to catch up with the emerging landscape of internet research (BSA 2002, BPS 2013, Bassett, E and O'Riordan K 2002). The internet has become embedded and has had an impact on research in all domains. However, research practices that deploy online methods are not supported by sufficient ethical guidance (Shapiro, R. B. \& Ossorio, P. N. 2013). This paper will aim to contextualise Internet Mediated Research (IMR) methods, consider how Higher Education Institutions are currently providing ethical review and guidance for projects using IMR methods, and explore the gap between the demands of research practice and HE ethical guidance. My paper will demonstrate work in progress to construct an argument for a reframing of research ethics for online research and provide discussion points of what this reframing may be.
\end{abstract}

\section{KEYWORDS}

Internet research ethics, Digital research

Over the last decade the internet has become embedded in the sciences, social sciences, arts and humanities, and has had an impact on research in all domains of Higher Education. However, there is a perception that research practices that deploy online methods, or examine internet mediated sites of social enquiry, are not supported by sufficient ethical guidance for Higher Education Institutions (Shapiro, R. B. \& Ossorio, P. N. 2013). There has been an attendant mediatisation and digitisation across all disciplines, which has led to the extension of internet methods across multiple disciplines. For example, audience studies of print or media culture are often conducted through internet review and discussion sites, rather than face to face focus groups. Some areas of study have become entirely digital, and in some cases new disciplines or sub-disciplines have arisen such as 'e-science' 'Internet Research' 'digital humanities'. This raises questions about how interfaces, such as research governance protocols, and research are managed. Over the last 15 years there have been debates about whether these conditions require new ethical frameworks, or demand that researchers and 
institutions become expert in internet research, or whether they can be governed through existing protocols and ethical frameworks. The consideration of a case for e-ethics intersects with issues around open source, creative commons, big data, private/public and rights discourse, internet pervasiveness and mediatisation (boyd, 2012, Ruppert, 2015).

In light of these considerations, this paper explores if there is a case for e-ethics or for a reframing of ethics, to accommodate the new ethical issues research online raises of a methodological, epistemological and ontological nature (NESH, 2014), and brings together discussions on online research methodology and higher education issues. The method used to inform this paper is largely practitioner or workplace research, as the author specialises in research ethics, and in supporting higher education institutions to undertake research to the highest ethical standard. To frame this paper and to place it in my context and perspective, I am a practice-based researcher. Professionally I work in research ethics, integrity and governance. Much of what I present in this paper is what I have learnt in action and observations from my professional practice and perspective.

This paper is exploratory and does not make conclusions or final statements, empirical data and further exploration is required before conclusions can be determined. Even if, or when, conclusions are determined, due to the expanding and progressive nature of the internet and the technological affordances available to researchers such conclusions would need frequent review. Further on, the paper will explore the challenges of reaching determinations or conclusions for research online, in the context of an emergent environment. The paper acknowledges the difference in disciplinary approaches and the plurality of ethical standards across disciplines, but is a general exploration and does not pertain to a specific discipline or methodological approach.

Throughout the paper, the umbrella term, Internet Mediated Research (IMR), will be used to describe internet research. As this paper looks at ethical considerations of research, it indicates internet research that involves identifiable data or identifiers, engagement with people directly or indirectly, via lurking or observation. Internet research is defined by the Norwegian National Committee for Research Ethics in the Social Sciences and the Humanities (NESH, 2014) ${ }^{1}$ as:

1) research on the Internet as a phenomenon in its own right, its structure and technology (production systems, technical design, programs, codes, etc.);

2) use of the Internet as a research tool (collection of data and information using informants, surveys, archives, logs, algorithms, etc.); and

3) research on production, communication and interaction using the Internet (e-mail, social media, blogs, Internet forums, discussion pages, comments fields, or the use of computer games, search engines, web pages, etc.).

\footnotetext{
${ }^{1}$ Norway is the sole country to have specific ethical guidelines for IMR issued by the Norwegian National Committee for Research Ethics in the Social Sciences and the Humanities (NESH, 2014).
} 


\section{Offline and Online research - Institutional challenges}

There is common agreement that the basic principles of ethical research are ${ }^{2}$ :

- Autonomy. The participant must normally be as aware as possible of what the research is for and be free to take part in it without coercion or penalty for not taking part, and also free to withdraw at any time without giving a reason and without a threat of any adverse effect.

- Beneficence. The research must be worthwhile in itself and have beneficial effects that outweigh any risks; it follows that the methodology must be sound so that best results will be yielded.

- Non-maleficence. Any possible harm must be avoided or at least mitigated by robust precautions.

- Confidentiality. Personal data must remain unknown to all but the research team (unless the participant agrees otherwise or in cases where there is an overriding public interest, or where participants wish their voices to be heard and identified).

- Integrity. The researcher must be open about any actual or potential conflicts of interest, and conduct their research in a way that meets recognised standards of research integrity.

The use of the internet, as demonstrated by the demonstrative examples, raises ethical issues around:

- whether to disclose or identify yourself as a researcher

- how to seek informed consent

- how to verify the quality of consent and understanding

- how to verify age and identity

- how to navigate the complexities of public, private and relational issues - not just the research participant but their close network

- and to consider ethically not just the method but also issues raised by the platform or media used.

Annette Markham ${ }^{3}$ (2015) explored the idea of shifting from basic principles and error-driven ethics to process-based and question-driven ethics, in order to shift from regulation to concept to process. This would allow a contextualised ethics process of decision-making which is live throughout the research activity, allowing for professional discretion and self-reflexivity. In the UK, ethical review is front-loaded where anticipated risks, burdens and benefits, methodology, method of recruitment etc. are all determined as part of an ethical review process which determines how the research will be conducted. Most processes have the flexibility to permit amendments, but this not the same as an ethics process being live throughout a research activity. Professional discretion is permitted with some disciplines -

\footnotetext{
${ }^{2}$ The Association of Research Ethics Committees 'Framework of Policies and Procedures for University Research Ethics Committees' 2013

${ }^{3}$ Conference proceedings given at the British Association of Applied Linguists SIG workshop on the Ethics of Online Research Methods, 17 April 2015
} 
for example, when using ethnographic methods (Murthy, 2008) - and not for others, where it is easier to anticipate risks, burdens and benefits due to a more limited protocol.

After exploring the case studies to consider these issues, it is evident that basic ethical principles apply to Internet Mediated Research (IMR) methods as with any research methodology, but require further consideration when applied to online research due to the new methodological and epistemological issues and considerations the internet raises.

Researchers that wish to use online spaces for research need to be supported adequately by their institution. A common area of difficulty is research ethics committees' perceptions or understanding of online research. A gap is evident between the demands of research practice and ethical guidance available or used by Higher Education Institutions. The standpoint that offline is significantly different from online research is also critiqued and problematized and this view may be caused by a naivety in understanding 'online research' from an institutional perspective. McKee and Porter $(2009,31)$ state that "often organisations simply cannot keep up, providing internet researchers with too little guidance and inappropriate guidance that applies overboard generalisations or make false comparisons between offline and online research." These generalisations and disproportionate caution is a manifestation of the lack of guidance available to research ethics committees; however, it is important to acknowledge this is not a universal experience across all researchers or institutions.

Expectations and standards for requiring ethical review for online research involving humans as participants or informants, knowingly and not knowingly participating, vary nationally and internationally. In the UK, across institutions, funders and professional bodies, there is an uncertainty and lack of knowledge, but predominantly online research methods involving people, directly or indirectly, are considered human participation, and therefore require ethical review. Murthy (2008) states that the ethics behind new media-driven research cannot be overstressed, but professional scholarly organisations and methods literature alike are ambiguous on the subject; Murthy points to the Association of Internet Researchers as an exception. Some Institutional Review Bodies (Research Ethics Committees in the US), and other professional membership bodies in the US, do not regard online research as human participation, particularly where methods are indirect, and they are therefore exempt from requiring ethical review. The NESH guidelines (2014) reflect a shift in understanding responsibility from singular or individual to relational. Ess (2007) has suggested that the Norwegian guidelines define ethical responsibilities in research as shared and distributed, not just for a research participant but also their networked relations; the consideration of networked relations where an individual's secondary or tertiary online profiles and all of their other linked relations are potentially implicated in any research involving that individual.

Omitted from the discourse of shared responsibility is the responsibility of the directors or owners of social media sites: “...the researcher must look beyond standard modes of operation in or to fulfil obligation on all levels. Despite them being obvious points, one must actually heed the fact that online activities are cross-border, one must consider the ethical 
aspects, such as the question of whether gathering information may be problematic even if the data is freely available, and one will have to consider commercial interests to a perhaps greater degree than the usual political ones" (Staksgrud 2015, 99). The discourse of shared responsibility, defining private and public space, with the compounding issue of difference in perception of private or public and behaviour around privacy, which pushes shared responsibility on to researchers and internet users but not onto the companies which own the platforms, and therefore developing data usage and privacy policies. This allows the "ethical free pass", as described by Arthur quoting Masnick (The Guardian, 2014), because a user has been obligated to agree to terms and conditions in order to use an app, social media site or online platform.

To begin exploring some of the new ethical considerations internet research raises, this paper will draw on illustrative examples to reflect on research practice. These examples demonstrate different issues pertaining to platforms, user understanding, protecting participants, risks to researchers, researching with groups, use of deception, and balancing disruption of communities with disclosure of researcher identity.

\section{Illustrative examples}

\section{i. $\quad$ Permissible data usage on social media}

Claire Hardaker ${ }^{4}$ researches aggression, deception and manipulation online, and behaviours such as flaming, trolling, cyberbullying and online grooming. Hardaker collects large datasets from Twitter for linguistics, textual and network analysis. This research practice has identified many ethically challenging considerations for the researchers, for example: what can be done when you start to identify people or if you can begin to identify their 'friends' through secondary or tertiary links to online profiles or relational identifiers. The researcher potentially also becomes identifiable by following certain individuals; participants (who know or do not know they are being monitored) are able to identify and follow the researcher back on Twitter, unless the researcher has mitigated against this by being covert or anonymous, which has further ethical considerations.

Hardaker's work demonstrates that in online research it is not solely about the consideration of method, but about the platform or media used, that can add on further ethical challenges for the researcher. Elgesum $(2002,197)$ acknowledges that the media often have an agenda

\footnotetext{
${ }^{4}$ The reflections on Hardaker's research ethics and practice are from "The ethics of online aggression: Where does "virtual" end, and "reality" begin?", conference proceedings of an Ethics of Online Research Methods workshop held by the British Association for Applied Linguistics Language and New Media Special Interest Group held at Cardiff University, 16-17 April 2015.
} 
that is different than that of a research project; this leaves the researcher to navigate these complexities.

Murthy $(2008,845)$ acknowledges the benefit and value that researching on social media has for ethnographers:

(1) they are virtual 'gatekeepers' with chains of 'friends' who are potential research respondents;

(2) they contain vast stores of multimedia material regarding even the most marginal social movements or groups;

(3) ethnographers can 'invisibly' observe the social interactions of page members, gleaning a previously unavailable type of ethnographic data;

(4) pages can be created by social researchers with the explicit purpose of conducting research online (e.g. focus groups watch an embedded video and comment on it);

(5) the structure of relationships on the sites is a useful research method itself with, as Garton et al. (1999: 78) argue, the content, direction, and strength of the relationship 'strands' a fruitful approach;

(6) pages can be created by social researchers to disseminate useful information to the public, an approach taken by the creators of the 'Cure Diabetes' MySpace page (Barsky and Purdon, 2006).

The NESH (2014) guidelines state that "Researchers must not assume that all Internet users have a conscious view of or knowledge of which information will actually be made public and which information will not be made public." Hardaker questions how informed twitter users are about how their data are being used. Crawford (2009) observes that Twitter is a young platform where the norms of use are nascent and contested. Latour described social lives as being traced by their circulation (Latour 2005, 13), which brings together the discourse of traceability, circulation and relational connections to the additional concerns brought about by social media platforms. As a researcher, the press requirements from Twitter ask that to quote a tweet the whole handle must be used and the quote must not be paraphrased unless there are exceptional circumstances, which makes anonymising, in the consideration that a user may not fully understand how their tweets may be used, challenging. There is also a consideration for the quality and accuracy of data; if the researcher is paraphrasing a tweet, being used for research data, how accurate and valid those data are once manipulated can be questioned.

The difficulty with privacy is that concerns about privacy are often not expressed in internet users' behaviour (Spiekermann et al 2001). The MRS Delphi Report ${ }^{5}$ about privacy stated that " $92 \%$ of Apps are free and consumers know that they are because their data is collected and used. It's a trade that is accepted but not always understood." Elgesum $(2002,202)$

\footnotetext{
5 Acknowledgement: Panel: Privacy, ethics and publicness in digital media environments Ansgar Koene "Participant consent and withdrawal when using publicly archived data" HORIZON Digital Economy Research, University of Nottingham BAAL SIG workshop on the Ethics of Online Research Methods 17 April 2015
} 
describes the function of research ethics as to help secure that people's expectations about the processing of information about themselves are not undermined.

"It is problematic for researchers to navigate and consider the ethical positioning of using platforms to collect data where there is a trade between use and data sharing in users' terms and conditions. There is a concern that users may not fully conceive of how their data may be used even if the use of those data are legal. Is there a call for research specific platforms like Prolific Academic ${ }^{6}$ or Call for Participants ${ }^{7}$ so that researchers do not need to balance the interests of the research, the participant and the complexities arising from the online platform itself?

Much of the discussion around internet research ethics is led by privacy protection discourse and public/private discourse. Can we rely on a public/private distinction at all when the space is radically different from research governed by traditional research ethics informed by offline research? Is the perception of the distinction of private/public reliable or are these distinctions too fluid to separate out? There is a substantial amount of public debate around private data and data protection, especially around the issue of surveillance and less so within the context of academic research. The NESH (2014) guidelines for internet research states that one of the definitions of interest research is the use of the Internet as a research tool (collection of data and information using informants, surveys, archives, logs, algorithms, etc.). The NESH guidance for social sciences and humanities states that (Elgesum 2002), for archive materials such as health registers, the norms of consent can be lifted as there is little risk of harm or reduced autonomy by giving access to those data. But how or when does data online reach a status of archived material, which is therefore potentially giving little risk of harm or reduced autonomy to those individuals whose data inform the archive material? Is there a temporal factor of proximity, between 'liveness' of data to no longer relevant material, which, if used, would not pose a risk to the individual who informed those data?

An emotional contagion study undertaken in 2012 allowed research on social media to receive public scrutiny due to the public concern raised around it. The study, undertaken by a Facebook data science researcher and two researchers from Cornell, investigated emotional contagion on Facebook by manipulating 700,000 users' news feeds. Although this number sounds high, it was only $0.04 \%$ of Facebook users whose feeds were manipulated for seven days. This does not minimise the effect on the users whose feeds were manipulated but brings into proportion the percentage of users involved. Following the scandal and public uproar that the researchers did not inform users or seek informed consent, Proceedings of the National Academy of Sciences (PNAS) ${ }^{8}$ initiated an investigation into the study. The project did not have ethical approval because the collaborating academics were from US universities and did not require ethical review according to the University research governance framework. As one of the researchers was from Facebook, Adam Kramer, Facebook have begun to look at

\footnotetext{
${ }^{6}$ Prolific Academic site http://www.prolific.ac/, it's acknowledged that this site is purely for recruitment but acts as an example of academics taking the online world into their own hands.

${ }^{7}$ https://www.callforparticipants.com/

${ }_{8}^{8}$ PNAS statement about the Facebook study http://www.pnas.org/content/111/24/8788.full
} 
their own internal review processes. In a Facebook article (Kramer 2014) Kramer publically apologised for the research methods chosen and stated that, in hindsight, the research benefits of the data collected may not have justified all of the anxiety the study caused.

Reflecting on the controversy sparked by the Facebook-led emotional contagion study, a researcher wrote: “As a researcher, you don't get an ethical free pass because a user checked a box next to a link to a website's terms of use. The researcher is responsible for making sure all participants are properly consented. In many cases, study staff will verbally go through lengthy consent forms with potential participants, point by point. Researchers will even quiz participants after presenting the informed consent information to make sure they really understand 9 ." Under Facebook's data usage policy, consent is not required to use data for research purposes and, therefore, strictly looking at policies and acceptable usage of data, the researchers were not doing anything wrong (legally). However, the public, and other researchers, challenged the notion that this was acceptable, regardless of data usage terms and conditions, especially as the activity involved attempting to manipulate emotions and induce negative or positive emotions in the unknowing participants. There is not any evidence that suggests, apart from opinion polls, that Facebook users actually left the service following the study being published, which again speaks to the difficulty present in the difference between expressed concerns around privacy and expressed behaviour that researchers are asked to negotiate in this emerging research landscape.

\section{ii. $\quad$ Researching groups}

Gabriella Coleman, a cultural anthropologist researching hacktivism, is the author of Hacker, Hoaxer, Whistleblower, Spy: the many faces of Anonymous (Coleman 2014). Coleman is reflexive of the ethics of the research with Anonymous. She was keen to protect herself and protect her research participants (or informants) from exposure to risk of legal or criminal proceedings, and mindful of the ethics of her research practice, which is compounded by the moral positioning and ethical conundrums presented in actions by Anonymous members in the past, present and future. This has similar long-standing considerations to criminologists or sociologists researching illegal behaviours or activities; the traceability or potential of being identified is more complicated due to the digital breadcrumbs left behind in this kind of research, which Coleman mitigates against successfully.

"While much internet communication is often effectively public through greater visibility, traceability and permanence, it is not always apparent whether this makes it ethically acceptable to use such data freely for research purposes" (BPS 2013, 7). The nature of the permanence and traceability of data are changing from developing data governance legalisation at a European level (which extends beyond the European Union even if data are being held outside of the EU). The right to be forgotten (the right to request the removal of

\footnotetext{
${ }^{9}$ Arthur, Charles quoting Masnick, Max June 2014 http://www.theguardian.com/technology/2014/jun/30/facebook-emotion-study-breached-ethical-guidelinesresearchers-say Accessed 22/06/15
} 
data) is potentially problematic for research and needs further investigation. A researcher can access tools which can uncover removed data, which may or may not be considered hacking, or can potentially be using research data which has since been removed for an undisclosed reason. This opens up concerns around privacy, copyright and legalities for the researcher, and demonstrates that data online are no longer permanent; this constant flux must be negotiated by the researcher, again with little guidance. As Glough et al $(2014,2)$ state, "Technology is felt to move faster and differently than institutions and humans."

Coleman interacted with the group, which is one way of researching with communities. Lurking is described as a silent method of participant observation, an alternative way of researching with communities without disclosing the status of researcher and avoiding disruption of the community. Lurking is a common pejorative term for those who are present in public online spaces but do not prominently speak up. I would argue that this term has hampered our understanding of online spaces, and that the concept of listening offers more open and critically productive ground (Crawford 2009). The BPS states that the social responsibility for disruption of social structures is a key ethical consideration for internetmediated research (BPS 2013). BPS asks researchers to consider the extent to which proposed research study procedures and dissemination practices might disrupt/harm social groups (BPS 2013).

\section{Deception of Online Groups/Communities}

Brotsky and Giles (2007) published, in Eating Disorders, a study which involved assuming the identity of a fellow site user with an eating disorder. This was justified due to the defensiveness of the community and the anticipated disruption disclosing their identity as researcher would cause. Therefore, the researchers justified a covert and deceptive approach. The plausible persona successfully gained access to twenty-three separate groups in twelve protected synchronous pro-ana communication environments. It is estimated that data were collected from up to 356 individuals to research and seek understanding of the pro-ana community. This study has, since publication, received ethical critique. Developing a character and using deception to engage users, regardless of an alert to their potential vulnerability, has to be justifiable to, and approved by, an appropriate body, for example a research ethics committee (UK/EU) or institutional review board (US).

This case speaks to issues around identity, privacy and respect for research participants, which is encouraged by the Norwegian guidelines (NESH 2014). However, the British Psychological Society (BPS 2013) guidelines encourages balancing the pros and cons of disclosure and the potential of causing harm by disrupting online communities; the BPS guidance (2013) states "intrusions from researchers into spaces considered private by their users may be invasive, unwelcome and socially irresponsible. Where the scientific value of such research could be considered very high, this may lead to a researcher needing to make decisions about whether joining a group without disclosure as a researcher (i.e. undisclosed 
observation) might be most appropriate, in order to avoid disruption and potential harm (e.g. to group levels of trust and cohesion)."

Brotsky and Giles (2007) do acknowledge the lack of guidance available to them in their methods section; the authors state that "existing guidelines for offline research are inadequate for dealing with the plethora of ethical issues - some requiring extensive philosophical discussion around identity and personhood."

Glaser et al (2002, 189-90) observe that "the anonymity of the internet permits research into marginal groups for whom self-disclosure may have costs, and where participants may be suspicious of researchers and outsiders." Illingworth (2001) argues that internet research can be used where a sample population is small or hard to find. Nosek et al $(2001,168)$ state "the emergence of a large number of specialist internet fora can afford an efficient way to recruit subjects." In addition, Murthy (2008) argues that an ethnographic approach enables social scientists to de-marginalise the voice of respondents and acknowledge the greater intimacy that online research can afford participants. There are clear benefits to undertaking research online, and the internet has become embedded in all domains of research, however there are clear higher education sector or institutional failings to adequately support researchers and institutions themselves, so as to understand the complexities of online research.

\section{Re-framing e-ethics}

There are difficulties in identifying an ethical framework due to this being an emergent field and research landscape, taking into account the progress of technological affordances available to researchers. There are static considerations that have been present in longstanding discussions around information and computer ethics of privacy discourse, public/private distinctions, consent, anonymity and confidentiality, responsible research conduct and justifying coercion or deception. In order to identify or develop guidance that is appropriate, it is useful to consider what function ethical guidelines hold for research practice. Ethical guidelines are used to support ethical research practice by highlighting issues and pointing to ways of resolving issues, avoiding harm and mitigating against risk - guidelines are not prescriptive and do not provide algorithms or procedures to follow - they require room for balancing interests. Ethical guidelines exist to support researchers in identifying ethical considerations their project or study raises. Elgesem $(2002,197)$ describes the need for research ethics to arise when:

"...there are conflicts between the central interests of research - i.e., the interest in new and better knowledge - and other of interests that are external to the research process. Where research requires a balance of interests could be characterised by the following conflicts: between research and respect for the integrity and autonomy of research subjects (e.g. issues pertaining to information, consent, privacy); between the integrity of research and economic interests (in contract research, for example); and between the individual researcher's interest in 
getting publications and intellectual honesty (i.e., the problem of plagiarism and fraud in different forms)."

Crawford (2009) states that the rapid uptake of social media services will result in an accelerated development of norms, habits and conventions - there is the potential that what will eventually become customary assumptions, norms and habits will inform what is regarded as ethically sound or ethically dubious. Ess (2007) suggests a relational approach and plurality for a digital research ethics. Encouraging plurality helps to reflect the global concerns (for the internet, as a global context) where the researcher may be researching participants internationally, sometimes knowing where participants are and sometimes not (if the responses, for example to a questionnaire, are anonymised). Ethical responsibilities are defined by Ess (2007) and NESH (2014) as shared and distributed for a research participant and their networked relations; relational responsibility, as suggested by the NESH guidance, may help to mitigate against the relational complexities online research holds. It also drives responsibility as a researcher and user, encouraging full understanding of not just research methods but also the online platforms or media.

An ethical approach emphasising relationships, responsibilities, particularity, and partiality (Jaggar, 1992) would encourage caring, community and a shared collective responsibility. Its emphasis on relationships speaks to the NESH focus on relational factors of internet research. A shared collective responsibility may allow space for shared or collaborative working between researchers, the media and owners of, for example, social media companies, to work together in order to balance the interests of the research objective and a media or commercial agenda. Deontological and utilitarian approaches are driven by the singular, defining actions as right or wrong, positioned in western normative ideals. There are, of course, deontological constraints on the treatment of participants, in terms of what is unacceptable research practice (Elgesem 2002). Deontology is sometimes described as duty, obligation or rule based ethics, based on compliance with a normative set of rules. The utilitarian system of ethics is according to which the rightness or wrongness of an action should be judged by its consequences. The goal of utilitarian ethics is to promote the greatest happiness for the greatest number.

In the consideration of these differing approaches, the researcher community, institutions, professional bodies and regulatory authorities who set the ethical boundaries must consider what a utilitarian stance or a relational approach would look like, as well as what the pros and cons of those approaches are, from the perspective of researcher, institution, funder, stakeholder and member of the public or potential research participant.

With the consideration of ethical approaches, it could be asked if a radical reframing of ethics to accommodate an e-ethics is needed, and in the consideration of it being an emergent landscape, is it the right time to identify and pin down a framework? Can institutions develop their understanding in how they approach ethical review of online research to a more balanced, proportionate and facilitative perspective, as opposed to making false comparisons 
to offline research (McKee and Porter 2009, 31)? In the context of an emergent landscape, how can institutions do this? Due to the lack of empirical data, it is unclear how widespread and common false comparisons to offline research are. While research ethics committees lack guidance, it is equally the responsibility of the researcher to explain how others have used these methods online safely, what risks were anticipated and how the researchers mitigated against them and reflected on the current literature in the area. This may provide the reassurance that research ethics committees require in order to be confident of not just the research method or technologies but the landscape in which the research is being undertaken.

In addition to the challenge of identifying or developing an ethical framework for an emergent landscape and emergent technologies and practices, there is a great need for empirical data around HEIs' approach to online research. This is required in order to make an evidence-led case for a re-framing of ethics for online research. In turn, this will lead to understanding ethical review practices from an institutional perspective, and more active exploration of how different ethical frameworks can be applied both to ethical review, and to support for researchers and research ethics committees, in order to be informed about digital research, online research and internet research ethics.

\section{References}

Arthur, C (2014) 'Facebook emotion study breached ethical guidelines, researchers say' [online] 30 June. Available at http://www.theguardian.com/technology/2014/jun/30/facebook-emotion-studybreached-ethical-guidelines-researchers-say. Accessed 22 June 2015 Association of Internet Researchers (2012) Ethical Decision-Making and Internet Research: Recommendations from the AolR Ethics Working Committee Association of Research Ethics Committees (2013) Framework of Policies and Procedures for University Research Ethics Committees

Barsky, E. and M. Purdon (2006) 'Introducing Web 2.0: Social Networking and Social Bookmarking for Health Librarians', Journal of the Canadian Health Library Association 27(3): pp65-7

Bassett, E and O'Riordan. K. (2002) 'Ethics of Internet Research: contesting the human subjects research model' Ethics and Information Technology, 4 (3): pp23247.

Berry, D M (2004) Internet research: privacy, ethics and alienation - an open source approach. Internet Research Vol.14(4), pp.323-332

Boyd, D \& Crawford, K (2012) Critical Questions for Big Data, Information, Communication \& Society, 15:5, 662-679

British Psychological Society (2013) The Ethics of Internet Mediated Research British Sociological Association (2002) Statement of Ethical Practice 
Brotsky, S.R. and Giles, D., (2007) Inside the "pro-ana" community: A covert online participant observation. Eating disorders Vol.15 Iss2 pp. 93-109.

Coleman, G (2014) Hacker, hoaxer, whistleblower, spy: the many faces of Anonymous London: Verso

Consalvo, M \& Ess, C (2013) The Handbook of Internet Studies. Wiley-Blackwell

Crawford, K., 2009. Following you: Disciplines of listening in social media.

Continuum: Journal of Media \& Cultural Studies, 23(4), pp.525-535.

Elgesem, Dag (2002) What is special about the ethical issues in online research? Ethics and Information Technology 4, 3 pp.195-203

Ess, C. (2007) 'Internet research ethics' The Oxford Handbook of Internet Psychology pp487-502. Oxford University Press

Ess, C. (2013) Digital media ethics. Polity

Fielding, N \& Lee, R. M (2008) The SAGE Handbook of Online Research Methods London SAGE

Garton, L., C. Haythornthwaite and B. Wellman (1999) 'Studying On-Line Social

Networks', in S.G. Jones (ed.) Doing Internet Research: Critical Issues and

Methods for Examining the Net, pp. 75-106. Thousand Oaks, CA: SAGE.

Glaser J., Dixit, J. and Green, D.P. (2002) Studying hate crime with the internet: what makes racists advocate racial violence? Journal of Social Issues, 58, 1

Glough, P, Gregory, K, Haber, B \& Scannell, J (2015) The Datalogical Turn in NonRepresentational Methodologies: Re-Envisioning Research Vannini, P Routledge p146

Illingworth, N (2001) The internet matters: exploring the use of the internet as a research tool Sociological Research Online Vol 6 (2) Accessed at www.socresonline.org.uk/6/2/illingworth.html

Hughes, J. ed., 2012. SAGE internet research methods. Sage.

Hunsinger, J and Krotoski, A (2010) Learning and researching in virtual worlds Learning, Media and Technology Vol.35(2), pp.93-97

Ingierd, Helene and Hallvard Fossheim (Eds.) (2015) Internet Research Ethics, Oslo: Cappelen Damm Akademisk, pp. 98-121

Jaggar, A. M (1992) Feminist Ethics, In Lawrence C. Becker \& Charlotte B. Becker (eds.), The Encyclopaedia of Ethics. Garland Publishing

Kember, S, and Zylinska, J. (2012) Life after new media: Mediation as a vital process. MIT Press

Koene, A (2015) 'Participant consent and withdrawal when using publicly archived data' Panel: Privacy, ethics and publicness in digital media environments BAAL SIG workshop on the Ethics of Online Research Methods 17 April 2015 University of Cardiff

Kramer, A (2014) Untitled [online] Facebook 29 June Available at www. facebook.com Accessed 22 June 2015

Krotoski, A (2011) Wikileaks and the New, Transparent World Order Political Quarterly Vol. 82(4), pp.526-530 
Krotoski, A (2010) Technology: Libraries of the future Nature Vol. 468(7324), pp.633633

Latour, B. (2005) Reassembling the Social an Introduction to Actor-network-theory Oxford: Oxford University Press UK

Mann, C. \& Stewart, F. (2000) Internet Communication and Qualitative Research (A Handbook for Researching Online)

Livingstone, Sonia, Kjartan Ólafsson and Elisabeth Staksrud (2013) Risky Social Networking Practices Among 'Underage' Users: Lessons for Evidence-Based Policy, Journal of Computer-Mediated Communication 18 pp. 303-320

Markham, A and Baym, N (2008) Internet inquiry: conversations about method. London: Sage

Mann, C and Stewart, F (2000) Online Communication and Qualitative Research: A Handbook for Researching Online. SAGE, London

Markham, A "Disrupting top down frameworks for ethics: A proactive approach to 'doing the right thing' in digital research" Plenary session BAAL SIG workshop on the Ethics of Online Research Methods 17 April 2015 University of Cardiff

McKee, Heidi A. \& Porter, James E. (2009) The ethics of Internet research: a rhetorical, case-based process p.31

McBride, N K (2014)"ACTIVE ethics: an information systems ethics for the internet age", Journal of Information, Communication and Ethics in Society, Vol. 12 Iss 1 pp.21-44

MRS Delphi Group Report (2015) ‘Private Lives?' [Online] Available at https://www.mrs.org.uk/campaign/video/privacy Accessed 22 June 2015

Murthy, D., 2008. Digital ethnography an examination of the use of new technologies for social research. Sociology, 42(5), pp.837-855.

The National Committee for Research Ethics in the Social Sciences and the Humanities (2014) Ethical Guidelines for Internet Research

Nosek, B.A., Banaji, M.R. and Greenwald, A.G. (2002) E-Research: Ethics, security, design, and control in psychological research on the internet, Journal of Social Issues, 58, 1, pp177-93.

Ruppert, Evelyn (2015) Who Owns Big Data. Discover Society (23),

Shapiro, R. B. \& Ossorio, P. N. (2013) Regulation of Online Social Network Studies Science Vol. 339

Scharf, B. (1999) Beyond Netiquette: The Ethics of Doing Naturalistic Discourse Research on the Internet. In Steve Jones, editor, Doing Internet Research, pp. 243-256. Sage, London

Spiekermann, S., Grossklags, J., \& Berendt, B. (2001, October). E-privacy in 2nd generation E-commerce: privacy preferences versus actual behaviour. In Proceedings of the 3rd ACM conference on Electronic Commerce (pp. 38-47). ACM.

Spiekermann, Sarah, Jens Großklags, and Bettina Berendt (2001) "Stated Privacy Preferences versus actual behaviour in EC environments: A Reality Check." eFinance. Springer Berlin Heidelberg pp.129-147. 
Staksrud, E (2015) 'Counting Children. On research methodology, ethics and policy development', in Helene Ingierd and Hallvard Fossheim (Eds.), Internet Research Ethics. Oslo: Cappelen Damm Akademisk pp. 98-121

Tagg, C and Spilioti, T (2015) Summary of conference proceedings of the The Ethics of Online Research Methods workshop held at Cardiff University 16-17 April 2015

Twitter (2012) 'Terms and conditions' [Online] (version 6) May 2012. Available at https://twitter.com/tos/previous/version_6?lang=en . Accessed 22 June 2015

Isla-Kate Morris is the Research Integrity and Governance Manager at University of Southampton. She has a great interest in Research Governance, Research Ethics and Integrity in HEIs. Isla previously worked for UK Higher Education Institutions and UK Royal Medical Colleges, working on Department of Health funded clinical research studies and clinical audit. Isla has presented across the UK and EU on digital research ethics, research integrity, bioethics, children in research and the governance of human tissue archives. Isla would like to thank the University of Sussex for providing funding and support on this article.

Email: i.morris@soton.ac.uk 